\title{
Compulsory treatment in the community: current legal powers Steffan Davies
}

Reform of mental health legislation has been under consideration for several years in England and Wales (Department of Health, 2000a), where the Mental Health Act 1983 is in force, and in Scotland (Millan Committee Secretariat, 2001), which is governed by the Mental Health (Scotland) Act 1984. The Mental Health (Northern Ireland) Order 1986 is also under review, although the findings have yet to be published.

Although there are no current proposals to introduce compulsory community treatment in Northern Ireland, the introduction of the 'community treatment order' has been a Government priority in England and Wales for some time. When announcing the review of the Mental Health Act 1983, Paul Boateng (then Health Minister) stated that 'non-compliance with agreed treatment programmes is not an option' (Department of Health, 1998). The proposals for reform of the Act include compulsory assessment and treatment in the community without hospitalisation, stressing the importance of public protection. Scottish proposals for mental health law reform are more balanced but also include a community care order (Millan Committee Secretariat, 2001). Given the high probability that community treatment orders will be introduced (although, given pressures on parliamentary time and the complexity of the proposals, it is impossible to predict a time-scale for these changes) it is timely to review UK and international experience of compulsory treatment in the community.

There are currently six legislative mechanisms for encouraging compliance with treatment in the community in England and Wales, all with parallels in Scotland (Box 1). There is surprisingly little published research on the use of legal powers in the community. This article reviews the existing powers and the literature relating to their use and effectiveness.
Non-legal strategies to encourage compliance with community treatment - such as assertive outreach and concordance therapy - also play an important part in clinical practice, but the interrelationship between legal and clinical strategies is unclear.

\section{Civil powers}

\section{Leave of absence}

A recognised practice before (and for a short time after) the introduction of the Mental Health Act 1983 was the 'leave of absence'. Compulsorily hospitalised patients would be discharged from hospital on extended leave of absence ('section 17 leave', under the 1983 Act), readmitted at the end of the period of compulsory admission for renewal of the section,

Box 1 Legislative mechanisms governing compliance with psychiatric treatment in the community

Leave of absence

Guardianship

After-care under supervision (supervised discharge) (England and Wales) or community care orders (Scotland)

Hospital orders with restriction orders

Probation orders with conditions of psychiatric treatment

Parole or a life licence with a requirement to comply with psychiatric treatment

Steffan Davies is a senior lecturer in forensic psychiatry at the University of Leicester and an honorary consultant forensic psychiatrist at Rampton Hospital (Retford, Nottinghamshire DN22 0PD, UK; e-mail: drsteffand@aol.com). His research interests include community supervision and long-term outcomes from general rehabilitation and forensic services. 
and again sent on extended leave. Patients could not be forced to take medication in the community, but they could be recalled to hospital if they failed to comply with the conditions of their leave. This practice, sometimes known as the 'long-leash', was judged illegal in England and Wales in 1985 on the grounds that extended leave did not constitute hospital treatment. Sensky et al (1991) identified a group of 35 patients who had been treated under the extended leave system. They compared them with controls, matched for age, gender and diagnosis, who in the opinion of their consultants did not require compulsory treatment in the community. The extended leave individuals were less likely to have complied with treatment in the past 5 years and more likely to have had a history of serious dangerousness in the past year. There were fewer admissions and better compliance while on extended leave than in a mirror period before. For 13 patients whose extended leave was terminated owing to the legal ruling, one was placed on guardianship; one complied with followup; six were readmitted under the Mental Health Act 1983; two committed suicide; and three were lost to follow-up. Although not conclusive proof, this seems to be evidence that the practice of extended leave was identifying a high-risk group and providing some benefits in terms of improved compliance and reduced admissions.

Interpretations of 'hospital treatment' under the Act have allowed patients to continue to have their section renewed if, for example, they attend the hospital weekly for monitoring of mental state, drugtesting and medication (Taylor, 1999). The Mental Health (Patients in the Community) Act 1995 extended the maximum duration of leave of absence to 12 months.

In Scotland, extended leave of absence was not subject to legal challenge in the same way and the long-leash arrangement continued, in spite of questionable legality (Chiswick, 1993), until the introduction of the 'community care order' in the Mental Health (Patients in the Community) Scotland Act 1995. A survey of Scottish consultants prior to the introduction of the community care order found that $65 \%$ used extended leave of absence and of those who did not, only 3\% said they would definitely not consider using it. Consultants as a whole supported the use of extended leave of absence and rejected the proposed community care order (Atkinson et al, 1997). The most common diagnosis for patients on an extended leave of absence was schizophrenia (73\%; Scottish Executive, 2000a).

\section{Guardianship orders}

Guardianship orders in their current form were introduced in the Mental Health Act 1983 and the
Mental Health (Scotland) Act 1984. The grounds for guardianship orders are that: (a) a patient suffers from a mental disorder (mental illness, severe mental impairment, personality disorder or mental impairment); and (b) it is necessary in the interests of the patient's welfare or for the protection of others.

Two medical practitioners make the application but it is accepted by the local social services department or, in Scotland, the Sheriffs' Court. Guardianship orders confer on the guardian (usually a social worker) the power to require the patient to reside at a place specified; to attend for medical treatment, occupation, education or training; and to allow access to be given to specified individuals. Although patients are required to comply with the conditions of guardianship orders, there are no sanctions available in the face of non-compliance.

There is relatively little literature on guardianship orders. A recent survey in England (Shaw et al, 2000) concluded that guardianship orders were generally not widely used and there was marked variation in usage between authorities. On 31 March 1998 there were 690 guardianship orders current in 130 English local authorities, with 428 new cases the previous year. Department of Health (2000b) statistics show a steady rise from 238 in 1992 to 600 in 1999. There has been a general perception that guardianship orders have been used for people with mental impairment and older people with dementia. There is some evidence to support this in Shaw's survey: $22 \%$ were classified as mentally impaired or severely mentally impaired; $26 \%$ were over 75 years of age; $33 \%$ had a 'serious mental illness' schizophrenia or an affective disorder - and only $4 \%$ of guardianship orders were made by the courts. There have been descriptions of successful use of guardianship orders in the elderly (Wattis et al, 1990), the mentally impaired (Craig, 1988) and a younger group with functional psychosis (Wattis et al, 1990).

The Scottish Review of Literature Relating to Mental Health Legislation (Scottish Executive, $2000 b$ ) also reported variations in usage across the 176 guardianship orders made in 1998/1999. The omission, in the Scottish legislation, of the need for patients with mental impairment to be 'abnormally aggressive and seriously irresponsible' led to a higher proportion of guardianship orders being made for persons with learning disabilities (32\%) in this period. Other diagnostic groups were dementia (35\%) and alcohol-related brain damage $(18 \%)$. Lower usage for mental illness (14\%) probably reflects previous practice of using extended leave of absence.

Guardianship orders have not been widely used in comparison with the over 13000 hospital and treatment orders made in England and Wales in the 
years $1997 / 1998,1998 / 1999$ and $1999 / 2000$ (Department of Health, 2000c). Usage in Scotland has been more frequent in comparison with the 1092 section 18 and hospital orders in 1999/2000 (Mental Welfare Commission for Scotland, 2000). Guardianship orders have been criticised for a lack of real power and practical problems with making and processing applications, and social services departments (and Sheriff's Courts in Scotland) have sometimes been reluctant to use guardianship orders. Although in existence since the implementation of the 1983 and 1984 Acts, guardianship orders have not become part of routine psychiatric practice, although their use has increased more recently.

\section{After-care under supervision}

Supervised discharge (England and Wales) or Community Care Orders (CCOs) (Scotland) were introduced in the Mental Health (Patients in the Community) Act 1995 and came into effect on 1 April 1996. The passage of the Act caused great controversy and was widely seen as a politically driven and ineffective response to a number of high-profile homicides by mentally disordered offenders (e.g. Eastman, 1995; Atkinson et al, 1997). In Scotland, the CCO replaced the extended leave of absence and in effect weakened legal powers. A Department of Health (1993) working party had previously identified a target group for compulsory community treatment with the characteristics given in Box 2 . It estimated that 3000-5000 patients nationally might need to be subject to such an order.

Supervised discharge has many similarities to a guardianship order but also has a number of important differences. To be made subject to supervised discharge, a patient must already be detained under a treatment order or hospital order. Although involving social workers and the local authority in its application, the process is health driven. It is initiated by the responsible medical officer (RMO) (a consultant) and administered by medical records departments. The grounds for an application, in addition to having a specified mental disorder, are to 'help secure that he/she receives the after-care services so provided'. This has been described as sectioning the professionals as well as the patient. Supervised discharge creates two statutory professional roles, those of community supervisor (a community psychiatric nurse or social worker) and community RMO. In Scotland, the CCO application is made to the Sheriff's Court and creates the roles of special medical officer and after-care officer. The requirements placed on the patient are the same as for guardianship orders but with the additional power to 'take and convey' the patient to

\section{Box 2 Characteristics of 'revolving door' patients for whom a community treatment order may be appropriate}

Compulsorily admitted for mental illness

Improve with treatment

Discharged into the community with a care plan

Failure to comply with the care plan and consequent deterioration in mental health

Formally readmitted to hospital

'the place of residence, medical treatment etc.'. There is again no effective sanction in the face of persistent non-compliance. The Act advises clinicians to review the supervised discharge order and, if not effective, rescind it and consider an application for compulsory admission.

As with guardianship orders, supervised discharge has been used sparingly. The number of supervised discharge orders made in England and Wales has increased from 187 in the first year $(1996 / 1997)$ to 544 in 1999/2000 (Department of Health, 2000c). In Scotland, only 13 CCOs were made in 1999/2000 (Mental Welfare Commission for Scotland, 2000). Use has also varied widely between trusts; an English survey (Pinfold et al, 1999) revealed a range of 0-7 in 1997 and 0-29 in 1998. Other work by this group (Franklin et al, 2000), reported that over half the patients for whom supervised discharge was used had a diagnosis of dementia or mental impairment. The power to take and convey was used rarely. Patients on supervised discharge, in comparison with those subject to guardianship orders, were 'younger, less disabled, more violent and less likely to be living in staffed accommodation'. Franklin et al conclude that supervised discharge has achieved some of its aims but may only succeed with a small proportion of those who cause concern to services. Responsible medical officers reported a lack of effective sanctions as the main reason for not using supervised discharge, and that they might use community treatment orders more often.

Our own experience (Davies et al, 1999, 2001) has generally been positive. In Leicestershire (population 0.9 million) 22 patients were subject to supervised discharge in the first 18 months, rising after 3 years to 55 . This represented $5.7 \%$ of all supervised discharge orders made nationally in a district with around $1.9 \%$ of the England and Wales population. The first 22 patients all suffered from a major mental illness. They had a mean of 7.3 previous admissions and the mean length of the index admission was 257 days. They therefore seem to 
represent the group of revolving door patients identified in the Department of Health's internal review. Although not systematically studied, violent or potentially dangerous behaviour was a feature in a number of cases. After 18-36 months of follow-up, 12 remained subject to supervised discharge and 15 had not been readmitted to hospital. Only one patient had remained out of hospital throughout the equivalent period before supervised discharge. Survival out of hospital was longer in comparison to an equivalent period before supervised discharge (717 v. 607 days; $P=0.037)$. The power to take and convey was used only once; the patient agreed to comply with his/her treatment package and remained on supervised discharge at follow-up. After 3 years, almost every consultant in general, rehabilitation and forensic psychiatry had used supervised discharge at least once. Supervised discharge was not, however, successful in every case, and a small number continued to be 'revolving door' patients. Consultants commented on how bureaucratic supervised discharge was, the lack of effective sanctions and that care packages were often very resource-intensive.

Other countries have compulsory community treatment legislation similar to supervised discharge. This mostly exists in the USA and Australia but owing to legislation being at state rather than federal level, great variation exists. A group in North Carolina, USA has reported results of a randomised controlled trial on outcomes of involuntary outpatient commitment (IOC; Swartz et al, 1999; Swanson et al, 2000), which has much in common with supervised discharge and community care orders. In particular, although patients can be escorted by law officers to the clinic, medication cannot be enforced, and sanctions for non-compliance seem non-existent in the absence of grounds for redetention. In common with CCOs, IOCs are ordered by a court rather than by approval by a clinician, if patients meet the criteria at the end of a compulsory admission. Randomisation of those who consented $(88 \%)$ and who had not committed a serious act of violence before admission ( $82 \%$ ) took place. Benefits in terms of a reduction in violence and in rehospitalisation were claimed for some groups. The message is, however, more complex than simply subjecting patients to IOC. Those that benefited were subject to IOC for longer periods (over 6 months) and had frequent contacts with psychiatric services (more than three contacts per month). Violence seemed to be reduced in part by increased adherence to medication and by a reduction in substance misuse. For readmission (hospital recidivism) IOC was most effective in non-affective psychoses.

Existing evidence suggests supervised discharge is being used in the groups it was intended for, namely those with major mental illness and a revolving door history, but also possibly in higherrisk subgroups. Although it is likely that it is effective in some patients, it remains unclear which ones and why. There would, however, seem to be benefits in terms of greater survival in the community and reductions in hospitalisation and violent behaviour. American evidence suggests that intensive outpatient contact is required and benefits only become apparent after sustained follow-up of over 6 months. The effects are complex and depend on intensive input by psychiatric services as well as the legal framework.

\section{Criminal justice powers}

\section{Conditional discharge from a restriction order}

Restriction orders are made by crown (or higher) courts and restrict the discharge and transfer of patients also subject to a hospital order. A hospital order can be made if all the following criteria apply: after conviction for an imprisonable offence; on the evidence of two medical practitioners; on the evidence of a defined mental disorder; on the evidence of the court being of the opinion that it is the most suitable method of disposing of the case. A restriction order can be added to a hospital order if 'it appears to the court ... necessary for the protection of the public from serious harm' (Mental Health Act 1983).

The restriction order means that the Home Secretary or Secretary of State for Scotland is required to approve leave from hospital and transfer between hospitals. Discharge from the restriction order can only be by the Minister or a mental health review tribunal (MHRT). Discharge can either be absolute or, more usually, conditional. Conditionally discharged patients 'may at any time' be recalled by a warrant issued by the Secretary of State. English case law (Jones, 2001: para. 1-526, pp. 234-236) suggests the Home Secretary 'needs to balance the interests of the patient against those of the public'. Home Office \& Department of Health and Social Services (1987) guidance for social supervisors lists the following circumstances under which a report to the Home Office should be made:

- there is an actual or potential risk to the public

- when contact is lost or the patient is unwilling to cooperate with the supervisor

- when the patient's behaviour or condition suggests a need for further in-patient treatment

- when the patient is charged with or convicted of an offence. 
The mechanism of conditional discharge represents a very robust legal framework for ensuring cooperation with a community care package. As well as the power to recall once discharged, the discharge decision and care plan needs to be approved by either the Minister or an MHRT. Patients have usually been hospitalised for many years before discharge. Medical and social supervisors also must give regular reports to the Home Office providing external monitoring and further reminding them of their responsibilities. In England and Wales, 253 hospital orders with restriction orders were made in 1999 (in Scotland eight) and by the end of 1999 there were 1853 patients so detained (Johnson \& Taylor, 2000).

Conditional discharge from a restriction order has been subject to the most extensive research of any of the orders. The need for the Home Office to hold centralised data on all restricted patients means that there is extensive and unusually complete data available. A number of papers have been published by the Home Office Research Department describing outcomes in terms of re-offending for restricted patients and also comparisons with released prisoners convicted of similar offences. There are also data on recall to hospital of conditionally discharged patients but no systematic data on informal admissions or brief admissions under assessment orders (section 2). Between 1984 and $1993,17 \%$ of patients discharged by an MHRT and $12 \%$ of those discharged by the Home Secretary were recalled within 2 years (Kershaw et al, 1997a). Descriptions of non-offending outcomes are scarce but include a comparison between outcome for patients with psychopathic disorders and those with mental illness (Steels et al, 1998). Patients with psychopathic disorders had better social adjustment but a higher rate of re-offending.

Between 1993 and 1997,2\% of restricted patients were reconvicted of a sexual or violent offence within 2 years of conditional discharge. In comparison, a sample of discharged prisoners and those on community sentences, matched for criminal history and demographic factors, had an expected reconviction rate of $11 \%$. Comparisons between restricted patients and prisoners released on life licences, who are older on release (Kershaw et al, 1997b), revealed higher rates of reconviction (for any offence), within 2 years: $11 \%$ v. $5 \%$ for those with no convictions previous to the index offence; $17 \%$ v. $10 \%$ for those with previous convictions. For released prisoners (not subject to a life licence) over the age of 30 , reconviction rates at 2 years were $5 \%$ for those without a previous conviction and $41 \%$ for those with a previous conviction.

Conditional discharge is reserved for convicted patients for whom hospital treatment was felt appropriate at the time of sentence but who were felt to present a potential risk of serious harm to the public. These patients have longer hospitalisations almost exclusively in secure units. Their rate of recall is $12-17 \%$ after 2 years. In terms of reconviction they compare favourably with prisoners subject to determinate or community sentences but less well with prisoners released on life licence. Although providing a robust and partially evaluated framework, conditional discharge from a restriction order is reserved for high-risk patients who have been convicted and received a hospital disposal.

\section{Probation orders with conditions of psychiatric treatment}

Probation orders have had a statutory basis since 1907. With the development of out-patient services in the 1920s magistrates began inserting conditions of psychiatric treatment. This practice received statutory recognition in 1948. In 1997, 903 probation orders with conditions of psychiatric treatment were made - only $1.8 \%$ of all probation orders in England and Wales (Home Office, 1997). In Scotland, 128 probation orders with conditions of medical/ psychiatric/psychological treatment were made in 1999/2000, 2.2\% of the total (Scottish Executive, $2000 a$ ). There is very little literature on probation orders with conditions of psychiatric treatment and much of this concentrates on procedural issues or case studies.

For a court (England and Wales) to make a probation order with conditions of psychiatric treatment, in addition to the usual requirements to make a probation order it requires (Stone, 1998):

- evidence from approved medical practitioner (section 12(2) Mental Health Act 1983)

- that the offender's 'mental condition...requires and may be susceptible to treatment'

- that arrangements have been made for the treatment specified.

Courts have the discretion to make probation orders in a wide range of offences including very serious offences such as manslaughter. In practice, the majority of probation orders are made for acquisitive or summary offences. Between 1987 and 1997 the numbers of probation orders in England and Wales increased by a quarter but the use of psychiatric conditions declined both as a proportion and numerically (Home Office, 1997).

Although there are statistics produced by the Home Office on the use of probation orders with conditions of psychiatric treatment, there are very few published studies and no recent empirical 
studies. The most informative document is a thematic review published by Her Majesty's Inspectorate of Probation (1993). This examined the use of probation orders in a number of probation areas that used them frequently, studying probation records and interviews with supervising officers. The factors contributing to the success and failure of orders are given in Box 3. Many of these factors mirror the issues raised by independent inquiries held after homicides by psychiatric patients. The Probation Inspectorate estimated that around 60\% of orders were completed successfully, which, given the complexity of the cases, was felt to be a good outcome.

Our own work in Leicestershire (further details available from the author upon request) identified 33 patients subject to or recently finishing probation orders with conditions of psychiatric treatment in 1999. The most striking aspect of the population on probation orders was its hetrogeneity. Although the most common diagnosis was schizophrenia (42\%), the sample included patients with affective disorders, personality disorder, post-traumatic stress disorder and individual cases with ill-defined or no diagnosis. Offences for which a probation order with conditions of psychiatric treatment was made ranged from possession of cannabis to attempted murder. A substantial number (12) had been involved in violent incidents, some extremely serious, which did not lead to charges or convictions. At the time records were examined, 60\% had either completed the order successfully, complied to date

Box 3 Factors contributing to the success or failure of probation orders with conditions of treatment

Contributing to success

Good assessments

Understanding of respective roles and responsibilities

Good liaison and record-keeping

Clear risk-management procedures

Access to appropriate resources

Removal from a chaotic lifestyle

Vigorous proactive work by the probation officer

Contributing to failure

Generally the opposite of those above

Inappropriate orders

Conflicting recommendations

Complex personality problems

Lack of understanding about breach criteria or had not breached the order, despite problems usually with attendance. Of the remaining $40 \%$, half had breached their probation order for noncompliance and half for further offending. Many of the factors, good and bad, identified by the Probation Inspectorate's thematic review were present in the case records examined. As the probation population presumably has high rates of mental disorder similar to that of the prison population (Office for National Statistics, 1998) the low rate of probation orders with conditions of psychiatric treatment may represent a missed opportunity to engage mentally disordered offenders with psychiatric services.

\section{Psychiatric supervision as a condition of licence}

Prisoners released on licence from determinate and life sentences may be subject to a number of conditions in addition to standard conditions such as keeping in contact with their probation officer. Additional conditions can include receiving treatment as directed by a named doctor or psychiatrist. Failure to comply with the licence conditions or indicators of increased risk can lead to recall to prison. For prisoners serving a determinate sentence, the period on licence can be short and does not run until the final date of the sentence. For life sentence prisoners the licence runs for the rest of their lives but conditions can be relaxed if sufficient progress is made. (For comparisons between life licensees and conditionally discharged restricted patients see above.)

While providing a powerful incentive for complying with psychiatric supervision after release, personal experience has been that such conditions are rarely made, certainly for determinate sentence prisoners. Given the high rates of psychiatric disorder reported in sentenced prisoners (Office for National Statistics, 1998) this probably represents another missed opportunity to engage mentally disordered offenders in treatment. While there are studies on reconviction and recall of licensed prisoners there is little, if any, information relating to those identified as requiring psychiatric supervision.

\section{Proposals for legislative reform}

The proposals for reform of the Mental Health Act 1983 and the Mental Health (Scotland) Act 1984 contain a number of important changes to current legislation including assessment and treatment 
provisions that can apply in the community as well as in hospital. There will, however, be no provision for enforcing treatment in the community but admission to hospital will be an option in the face of non-compliance. For England and Wales they also include: a broader definition of mental disorder and the removal of more defined categories, such as mental illness and personality disorder; a move away from the 'narrow concept of treatability'; powers for MHRTs to reserve to themselves decisions on leave and discharge for civilly detained patients (in effect a civil restriction order). The Scottish proposals are more moderate, acknowledging the debate about the treatability of personality disorders, and do not propose a civil restriction order.

\section{Discussion}

A wide range of powers already exists to encourage or enforce compliance with psychiatric treatment in the community. Some, such as leave of absence or conditional discharge from restriction orders, are a routine part of clinical practice. Leave of absence is limited in duration and can be renewed only in certain cases. The courts can make restricted hospital orders after conviction, on certain risk criteria. They usually involve lengthy hospitalisation in secure units, and although useful for those convicted and perceived as being high-risk, they are not available for those high-risk patients not convicted.

Guardianship and probation orders with conditions of psychiatric treatment, although established, are seldom used and there is wide variation between areas. Guardianship has no sanction for non-compliance and has tended to be used more for the elderly and those with learning disabilities. Probation orders with conditions of psychiatric treatment are uncommon and potentially problematic for those not experienced in their use. Although there is a sanction in the form of breach proceedings, these can be slow to activate and uncertain in their results. Given the high rates of mental disorder in offender populations, probation orders are probably underutilised and could have a greater role in encouraging engagement with psychiatric services.

Supervised discharge is more controversial. On its introduction it satisfied neither those asking for effective community treatment powers nor those concerned with patients' civil liberties. The evidence available suggests that it could be beneficial in some cases in reducing hospitalisation and violent behaviour. Sensky et al's (1991) study suggested that the removal of a legal framework to encourage compliance could lead to adverse outcomes such as loss of contact with services, readmission and suicide. His finding of a reduction in hospital admissions and better compliance under the 'longleash' arrangement mirrors our own findings with supervised discharge. The choice in terms of civil liberties may not be as simple as being restricted by supervised discharge or not, but of a least restrictive option with the likelihood of re-hospitalisation being another factor in the equation.

Although the majority of psychiatric patients are not violent, there are suggestions that a violent subgroup may be more likely to be subject to supervised discharge. Violent offending in those in contact with psychiatric services has many victims in addition to the direct recipients - relatives and carers of the offender, psychiatric services in general and those with mental disorder who are further stigmatised.

There are grave concerns among psychiatrists over aspects of the proposed reforms of mental health law, especially the potential expansion in the numbers that could be subject to detention by relaxing the diagnostic and treatment criteria (Royal College of Psychiatrists, 2001). The case for community treatment powers is more complex but, at least in the mind of the current UK Government, proven. The uses of existing powers are patchy and poorly understood, but new legislation may help simplify and standardise practice, currently characterised by great variations. The introduction of, in effect, civil restriction orders residing with the MHRT may also address the problem of high-risk patients not covered by current restriction orders. If this is to be the case, adequate safeguards need to be available. Compliance/non-compliance with a care package exists as a spectrum of responses rather than a dichotomous condition. Legal powers are only part of any good care package and alternative strategies such as concordance therapy, more tolerable drugs, psychological therapies, supported accommodation and assertive outreach can also be effective individually or in combination. What evidence there is also suggests that existing powers are more effective for those with mental illness, in particular those with non-affective psychosis. There is a danger that stronger powers will lead to clinicians trying less hard to engage difficult patients - a good therapeutic alliance is likely to be the most potent predictor of positive outcomes in the community.

\section{References}

Atkinson, J. M., Gilmour, W. H., Dyer, J. A. T., et al (1997) Consultants' views of leave of absence and community care orders in Scotland. Psychiatric Bulletin, 21, 91-94. 
Chiswick, D. (1993) Compulsory treatment in the community in Scotland: ten questions and answers. Psychiatric Bulletin, 17, 424-425

Craig, A. (1988) Guardianship survey. Social Services Research, 4, 39-42.

Davies, S., Bruce, J. \& Fallows, S. (1999) Section 25 aftercare under supervision: the first eighteen months' experience. Medicine, Science and the Law, 39, 214-218.

- Fallows, S., Bruce, J., et al (2001) Early outcomes of supervised discharge. Medicine Science and the Law, 41, 3134.

Department of Health (1993) Legal Powers on the Care of Mentally Ill People in the Community: Report of the Internal Review. London: Department of Health.

- (1998) Press release - Review of Mental Health Act. 22 September 1998. London: Department of Health (available at http:/ / www.doh.gov.uk).

- (2000a) Reforming the Mental Health Act. White Paper. London: HMSO.

- (2000b) Guardianship under the Mental Health Act 1983. London: Government Statistical Service.

- (2000c) In-patients Formally Detained in Hospitals under the Mental Health Act 1983 and other Legislation, England: 1989-1990 to 1999-2000. London: Department of Health.

Eastman, N. (1995) Anti-therapeutic community mental health law. BMI, 311, 1081-1082.

Franklin, D., Pinfold, V., Bindman, J., et al (2000) Consultant psychiatrists' experiences of using supervised discharge. Results of a national survey. Psychiatric Bulletin, 24, 412 415

Her Majesty's Inspectorate of Probation (1993) Probation with Requirement for Psychiatric Treatment. London: Home Office.

Her Majesty's Prison Service (1999) Lifer Manual. Prison Service Order 4700. London: HM Prison Service.

Home Office (1997) Probation Statistics - England and Wales 1997. London: Government Statistical Service.

- \& Department of Health and Social Services (1987) Mental Health Act 1983. Supervision and After-care of Conditionally Discharged Restricted Patients. Notes for the Guidance of Supervising Psychiatrists. London: Home Office.

Jones, R. (2001) Mental Health Act Manual (7th edn). London: Sweet \& Maxwell.

Johnson, S. \& Taylor, R. (2000) Statistics of Mentally Disordered Offenders 1999 - England and Wales. Home Office Research and Statistics Directorate. London: Home Office.

Kershaw, C., Dowdeswell, P. \& Goodman, J. (1997a) Restricted Patients - Reconvictions and Recalls by the End of 1995 England and Wales. London: Home Office, Research and Statistics Directorate.

_- _ \& - (1997b) Life Licencees - Reconvictions and Recalls by the End of 1995: England and Wales. London: Home Office, Research and Statistics Directorate.

Mental Welfare Commission for Scotland (2000) Annual Report. Edinburgh: Mental Welfare Commission for Scotland.

Millan Committee Secretariat (2001) Report on the Review of the Mental Health (Scotland) Act 1984. Edinburgh: Scottish Executive.

Office for National Statistics (1998) Psychiatric morbidity amongst Prisoners in England and Wales. London: Stationery Office.

Pinfold, V., Bindman J., Friedli K., et al (1999) Supervised discharge orders in England. Compulsory care in the community. Psychiatric Bulletin, 23, 199-203.

Royal College of Psychiatrists (2001) Government White Paper on the Reform of the Mental Health Act 1983 (responses from the President, Registrar and Mental Health Law SubCommittee). http://www.rcpsych.ac.uk/college/ parliament/wp.htm.

Scottish Executive (2000a) Statistical Bulletin: Criminal Justice Series. Edinburgh: Scottish Executive.

- (2000b) Review of Literature Relating to Mental Health Legislation. Edinburgh: Scottish Executive.
Sensky, T., Hughes, T., \& Hirsch, S. (1991) Compulsory psychiatric treatment in the community. I. A controlled study of compulsory treatment with extended leave under the Mental Health Act: special characteristics of patients treated and impact of treatment. British Journal of Psychiatry, 158, 792-799.

Shaw, J., Hatfield, B. \& Evans, S. (2000) Guardianship under the Mental Health Act 1983. Psychiatric Bulletin, 24, 5152 .

Steels, M., Roney, G., Larkin, E., et al (1998) Discharged from hospital: a comparison of the fates of psychopaths and the mentally ill. Criminal Behaviour and Mental Health, 8, 37-53.

Stone, N. (1998) A Companion Guide to Mentally Disordered Offenders. Ilkley: Owen Wells.

Swanson, J. W. Swartz, M. S., Borum, R., et al (2000) Involuntary out-patient commitment and reduction of violent behaviour in persons with severe mental illness. British Journal of Psychiatry, 176, 324-331.

Swartz, M. S., Swanson, J. W., Wagner, H. R., et al (1999) Can involuntary outpatient commitment reduce hospital recidivism?: Findings from a randomized trial with severely mentally ill individuals. American Journal of Psychiatry, 156, 1968-1975.

Taylor, J. (1999) In-patient $v$. out-patient status (letter) Psychiatric Bulletin, 23, 440.

Wattis, J. P., Grant, W., Traynor, J., et al (1990) Use of guardianship under the Mental Health Act 1983. Medicine, Science E Law, 30, 313-316.

\section{Multiple choice questions}

1. Studies concerning supervised discharge and similar legislation have found:

a it most effective for those with non-affective psychosis

b frequent contact with services is unnecessary

c reductions in hospitalisation

d use of existing powers is widespread and uniform

e no suggestion of reductions in violence.

2. Proposed legislation to reform the Mental Health Act 1983 in England and Wales:

a will allow treatment to be enforced in the community

b more clearly defines treatability

c allows tribunals to reserve to themselves the power to discharge and grant leave for civilly detained patients

$\mathrm{d}$ allows compulsory assessment and treatment to take place in the community without hospital admission

e stresses public protection as a Government priority.

3 With regard to restriction orders:

a they can only be made after conviction for a serious offence

b they allow patients to be discharged only by the Home Secretary or a mental health review tribunal 
c conditionally discharged patients are less likely to be convicted of an offence than prisoners released on life licence

$\mathrm{d}$ they allow conditionally discharged patients to be recalled to hospital at any time by their responsible medical officer

e they allow conditionally discharged patients to be readmitted to hospital informally without being recalled.

4. Guardianship and supervised discharge:

a both require patients to reside where directed allow access to mental health professionals, and attend for treatment

b are both 'health-led' and administered by medical records departments

c patients on both can be 'taken and conveyed' to hospital

$\mathrm{d}$ have no effective sanctions in the face of noncompliance

e have both been subject to extensive research.
5. Probation orders with a condition of psychiatric treatment:

a are rarely made

b can only be made if arrangements have been made for treatment

c in studies have been successful in $60 \%$ of cases

$\mathrm{d}$ are made for the majority of mentally disordered offenders subject to probation supervision

e have had statutory recognition for over 50 years.

\section{MCQ answers}

$\begin{array}{llllll}1 & 2 & 3 & 4 & 5\end{array}$

a $\mathrm{T}$ a $\mathrm{F}$ a $\mathrm{F}$ a $\mathrm{T}$ a $\mathrm{T}$

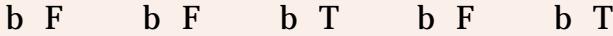

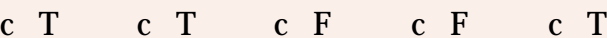

d F $\quad$ d T $\quad$ d F $\quad$ d T $\quad$ d F

e $\begin{array}{llllllllll} & \text { e } & \text { e } & \text { e } & \text { e } & \text { e } & \text { e }\end{array}$

